\title{
A Cross-Cultural Pragmatic Study: Politeness Strategies and Realizations of the Strategies Used to Perform Student- Lecturer Multiple Disagreements by Native Speakers of Thai and English
}

\author{
Charoenroop Pattrawut \\ English as an International Language Program \\ Chulalongkorn University, Thailand \\ E-mail: pattrawut.ch@gmail.com
}

Doi:10.5901/jesr.2014.v4n1p147

\begin{abstract}
This study examines what politeness strategies (cf. Brown \& Levinson, [1978], 1987) native speakers of Thai (henceforth abbreviated the NT) and Canadian English (the NE) use to perform the student-lecturer multiple disagreements in the classroom context. Generally speaking, the NT's culture is oriented towards collectivism, while the NE's tends towards individualism (Hofstede, 1991, 2001). Based on their cultural orientations, it is hypothesized that the NT and NE, despite performing disagreement in the same context, select the politeness strategies and realize the strategies differently. To prove the hypothesis, data were collected by means of classroom videotaping. Prior to the classroom videotaping, the participants' consents to involve in this study were endorsed. The purposive sampling method was used to select two sample groups representing the target populations. Their classrooms were videotaped for three hours every week for ten continuing weeks. The data were analyzed in terms of the politeness strategies and their realizations. In the context of this study, only multiple disagreements performed by the same students were analyzed. Results show that the NT disagree with their lecturer in only small numbers of turn-takings, whereas the NE often perform their disagreement in greater quantity. Although the NT and NE use the on-record strategy to initiate their first performance of disagreement, they both use different politeness strategy in the subsequent turns. The NT normally redress their politeness strategy and less often realize the strategy non-linguistically, but the NE usually aggravate the politeness strategy in the subsequent turns and realize their strategy non-linguistically, i.e. through the use of head shaking and facial expressions. To some extent, the hypothesis has been proved correct.
\end{abstract}

Keywords: Collectivist-Individualist cultures; Disagreement; Multiple disagreements; Politeness strategies

\section{Introduction}

According to Brown \& Levinson ([1978], 1987), disagreement is an intrinsic face-threatening act, having potential to threaten the addressee's positive face, i.e. the face to be liked or approved of. Brown \& Levinson mention three sociocultural variables, i.e. power, social distance and ranking of imposition, to be computed when the speaker interacts with the addressee. Brown \& Levinson provide five sets of politeness strategies, i.e. the on-record, positive politeness, negative politeness, off-record and don't do the face-threatening act (henceforth abbreviated FTA) strategies to be chosen. A selection of a particular politeness strategy over the others is dependent on the sums of the three sociocultural variables. The higher the sums of the socio-cultural variables, the more politeness strategy the speaker is expected to use. It is assumed that the use of the on-record strategy should be minimized particularly in a context where there is asymmetry in the power relationship between the speaker and the addressee, such as the classroom context. This is because the on-record strategy does not involve any redressive actions that help minimize levels of face-threats (cf. Brown \& Levinson). Several studies on disagreement performed by students in the classroom context (e.g. Hong, 2003; Liu 2004 and Walkinshaw, 2007, 2009) have extensively focused on the lecturer's power and have pointed out convincingly that the lecturer's unequal power does affect the students' use of politeness strategies in a predictable way. However, to understand why the students have to be polite can be controversial. Many studies in the same field (e.g. Rees-Miller, 2000; Kakava, 2002) have argued that other constraints (e.g. topics of discussion and severity of context) can also contribute to an appropriate selection of a particular politeness strategy. In other words, to understand why native speakers of both languages often begin their disagreement with the use of the on-record strategy can be relatively complex. A single consideration of the lecturer's asymmetry in power standing may be insufficient.

Besides looking at all socio-cultural variables to understand what politeness strategy is appropriately chosen, it is interesting to investigate whether the performance of disagreement universally threatens the addressee's positive face. 
This has been studied by Wierzbicka (1991) when she examines Leech's (1983) "agreement maxim", i.e. motivating the speaker to maximize the agreement but to minimize the disagreement between self and others cross-culturally. Results in her study show that the ideal concept of the cost-benefit scale to decrease disagreement between the speaker and the addressee is not necessarily true across languages and cultures. In some particular communities such as the JewishAmerican people, the performance of disagreement has potential to fortify people's solidarity and to unite their in-group social relationship. In the Jewish-American culture, the performance of disagreement does not jeopardize the people's harmonious affiliation, as generally expected. Wierzbicka's (1991) findings, for example, have urged for further studies in the cross-cultural sub-field to be conducted because the more the numbers of cross-cultural studies are increased, the less intuitions can mistakenly occur, particularly to avoid over-generalizing the dispreference of disagreement across languages and cultures. Based on the issue of over-generalizing, a review of literatures on disagreement (e.g. ReesMiller, 2000; Kakava, 2002; Gudong \& Jing, 2005; Chen, 2006 and Xuehua, 2006) shows that the most typical group of English native speakers whose pragmatic norms are frequently referred to is the American. The repeated use of the American may restrict our perception towards other groups of English native speakers such as the British English, Australian English, Canadian English and New Zealand English, particularly when they perform their disagreement crossculturally. However, there have been small numbers of current pragmatic studies on disagreement (e.g. Thi Thu Hong, 2006; Walkinshaw, 2007; 2009) that use other native speakers of English to provide pragmatic norms. To use the Canadian to represent a group of native speakers of English can deepen cross-cultural awareness and perhaps avoid over-focusing on the explicit use of the American English native speakers as pragmatic norm providers.

\subsection{Collectivist-Individualist Cultures}

There are few studies on disagreement that have used other groups of native speakers of English than the American in order to study their pragmatic norms. A minimum, if not none, of the existing studies on disagreement reveals stereotypical characteristics of the Canadian based on their individualist culture. It can be crucial to understand typical characteristics of people from different countries because people of different countries speak in different ways. Wierzbicka (1991) argues that it is not just because people do speak in different codes but in fact the ways the codes are used are completely different. Wierzbicka's argument is supported by Hofstede's $(1991,2001)$ concept of cultures that vary across countries. Hofstede claims that cultures can significantly govern their people's linguistic behaviors. He proposes the model of culture to describe typical characteristics of people from different countries. There are four ${ }^{1}$ components in Hofstede's $(1991,2001)$ model of culture. One of them is the collectivist and individualist dichotomy. The two sample groups in my study, i.e. the NT and the NE, are examples of highly collectivist and individualist cultures respectively. To say that their linguistic behaviors are different should also consider their collectivist and individualist cultures explained by the given statistical percentage. It is discovered that the percentage used to describe the Canadian's individualism equals 80 percent, which is relatively high and comparable to that of the American (91 percent). The figures suggest that both the Canadian and the American tend to be highly individual, causing them to value personal independence as the paramount importance. Their society is egalitarian rather than hierarchical. They are competitive and ambitious. Regarding the way they use their language, they tend to be direct with communicative means of explicit wordings and gestures. In opposition, Hofstede's $(1991,2001)$ statistical percentage shows that the Thai people are oriented towards collectivism, (their individualist percentage equals 20). This small percentage suggests that the Thai typically place high values on deference and respect of authority. In Thai culture, social harmonies are strongly emphasized and maintained. Although the collectivist-individualist dichotomy can only describe people at their surface level, it may be possible to elucidate why the NT and NE choose different politeness strategy and realize the respective strategies in different fashions.

\subsection{Disagreement}

Pomerantz (1984), Schiffrin (1984), Sacks (1987) and Kakava $(1993,2002)$ define disagreement as a responsive act, which must rely on the preceding utterance. In other words, disagreement cannot be performed without the presence of an initial utterance. In this study, disagreement is only produced by the students when they aim to state a different opinion against the lecturer's preceding utterance or to correct their lecturer's mistake. The former is illustrated in Example 1, while the latter is depicted in Example 2. In the following examples, $L$ stands for the lecturer and $S$ for the

\footnotetext{
${ }^{1}$ The four dimension of Hofstede's (1991, 2001) model of culture comprises (1) power distance index (PDI), (2) collectivism and individualism (IDV), (3) femininity and masculinity (MAS) and (4) uncertainty avoidance (UAI).
} 
student, Ss refers to many students and S1, S2 or S3 help indicate that each utterance is spoken by different students. The conventions of paralinguistic features used in this study are enclosed in Appendix I.

Example 1: (the student aims to state his different opinion)

1. L: (the lecturer showed a red color on the screen) Can you tell me what color is this $(/)$

2. S: Orange $(/)$

3. L: No:: RED RED

4. S: Oh it doesn't look red to me

Example 2: (the student aims to correct a mistake)

1. L: (the lecturer wrote a punctuation mark [:] on the blackboard) Use a semi colon to indicate long vowels (short pause) in phonetics

2. S: Semi colon(l)

3. L: Semi colon is dot dot

4. $\mathrm{S}:(\mathrm{p})$ colon $(\mathrm{p})$

\subsection{Multiple Disagreements}

Past studies on disagreement (e.g. Gudong \& Jing, 2005; Xuehua, 2006; Walkinshaw, 2007, 2009) used the discourse completion tasks (abbreviated DCTs) to elicit their participants' disagreement responses. One of the DCTs' deficiencies lies in the fact that the DCTs rarely allow the participants to perform their disagreement in many turns (Kasper and Dahl, 1991; Cohen, 1996; Tseng, 1999; Yuan, 2001). Although there have been several improvements trying to abolish such weakness, the DCTs still cannot effectively support the participants to perform their disagreement in many turns. In this study, the students' performance of disagreement is not constrained by any elicited-based instrument. In fact, the naturally-occurring data were collected by means of classroom videotaping, making the students' performance of disagreement in multiple turns possible. In this study, multiple disagreements refers to the performance of disagreement by the same speaker, and such performance is carried out in more than one turn, as shown in Example 3, when the same student performs the disagreement in lines 4, 6, 8 and 9.

Example 3: (multiple disagreements performed by the same student)

1. L: Give me another word that ends with -ness

2. S1: Sorrowfulness

3. L: Yea:h yea:h sorrowfulness

4. S2: No (the student shook her head from side to side) not a word

5. L: IT IS: (short pause) SORROWfulness is an English word

6. S2: SorrowfulNESS( $/$ ) NO.... (the student shook her head from side to side)

7. L: It is in English

8. S2: (long pause) Not in English

9. S2: (long pause) Never heard of it

10. L: Really(/)

11. S2: I heard only SORROW

12. S2: (short pause) (p) It sounds really weird (short pause) sorrowfulness (p)

13. L: OK then (short pause) look it up in an online dictionary

\subsection{Politeness Strategies}

There are five sets of politeness strategies that are introduced by Brown \& Levinson ([1978], 1987). They are (1) the onrecord strategy, (2) the positive politeness strategy, (3) the negative politeness strategy, (4) the off-record strategy and (5) the don't do the FTAs strategy. The use of a particular strategy over the others can be determined by the sociocultural variables. Such variables, not only the power relationship and social distance, but also ranking of imposition, should be computed so that the most appropriate politeness strategy can be chosen. In this study, linguistic realizations are the major focus. Using the linguistic realizations as the major analysis, the don't do the FTAs, is thus excluded. Only four sets of politeness strategies are used in this study, namely (1) the on-record strategy, (2) the positive politeness strategy, (3) the negative politeness strategy and (4) the off-record strategy. 


\subsubsection{On-Record Strategy}

The on-record strategy is realized baldly with no redressive action (cf. Brown \& Levinson, [1978], 1987). To perform the disagreement directly without any softening devices, the speaker may realize the strategy with a negation marker, e.g. "no", to initiate the disagreement directly. In Example 4, the student repeated her disagreement three times (lines 5, 7 and 12) using the same negation marker "no". Taking a close examination of these negation markers, it is found that her expressions of the negation marker are realized differently. They are accompanied by different paralinguistic features, such as word stress, loud volume and lengthening vowels. Such paralinguistic features have made the on-record strategy aggravated (cf. Rees-Miller, 2000; Kakava, 2002; Hong, 2003).

Example 4:

1. S: How do I say (short pause) I don't want TOO spicy

2. S: (short pause) I want OK spicy

3. S: (long pause) That's what I want to say

4. L: "mai phed ma:k"=

5. S: =NO I WANT spicy=

6. L: =Yea::h BUT you want NOT TOO spicy

7. S: NO...: I want how they make it FOR (short pause) [YOU(l)

8. L: ["mai phed ma:k]

9. S: BUT they won't make it like THAT for me

10. L: "mai phed ma:k" "mai" means not "phed" means spicy ma:k means too much

11. L: (short pause) not too much spicy

12. S: (short pause) NO no no BECAUSE I am "farang2"

13. L: YE::S

14. S: Sometimes they make my dishes NOT TOO:: spicy

\subsubsection{Positive Politeness Strategy}

The positive politeness strategy is different from the on-record strategy in that it is softened, although directly realized. The redressive action has been made to satisfy the addressee's positive face-wants. The speaker aims to please the addressee's wants to be liked when the speaker performs the disagreement. Considering Example 5, the student disagrees with his lecturer in lines 6 and 7. Prior to his performance of disagreement, he performs the agreement in order to satisfy the lecturer's wants to be approved of. The presence of "but" in line 6 used as a discourse connective (Schiffrin, 1987) can be an indication of disagreement, particularly when it occurs within the turn and uttered by the same speaker.

Example 5:

1. L: What the chicken sounds like in English(I)

2. S: kwak kwak kwak kwak kwak

3. L: Really $(l)$

4. S: YES

5. L: Not cockadoodledoo(/)

6. S: Yes COCKadoodledoo:..: BUT that's MALE

7. S: Rooster (p) not chicken (p)

\subsubsection{Negative Politeness Strategy}

The negative politeness strategy is similar to the positive politeness strategy in that it is realized baldly but the realization is redressed. The only difference derives from the fact that the redressive action has been made to satisfy the addressee's want to be free from imposition. In Example 6, the student disagrees with her lecturer in lines 13 and 14. The uses of the conditional sentence structure, showing that the speaker tries to avoid openly imposing on the lecturer, and of a hedging device in line 14, i.e. probably, increase the degrees of probability and decrease the degrees of certainty. The presence of long pausing prior to the student's performance of disagreement in line 13 can be an indication that the student does not want to impose on the lecturer's face, making her performance of disagreement

2 "Farang" is a Thai proper noun used to address all Westerners or Western-like people. The term is applied to everyone who looks like a Westerner with no consideration of their particular nationality. 
relatively delayed.

Example 6:

1. L: If you meet someone at 12 sharp (short pause)

2. L: What do you say (short pause) in in English

3. Ss: (silence)

4. L: l'd say (short pause) good morning(/)

5. S1: Good afternoon

6. S2: At twelve(/)

7. L: YE::S at twelve sharp=

8. S2: $=$ Good DA:Y

9. Ss: (all students laugh)

10. S3: (long pause) NOO::N

11. L: Good noo::n(l)

12. Ss: Good noo::n (all students laughs)

13. S2: (long pause) WELL if it's exactly noon

14. S2: That's probably two or three seconds after the things come out of your mouth

15. S2: Then IT's afternoon (laughs)

\subsubsection{Off-Record Strategy}

The off-record strategy is different from the direct strategies mentioned above. This strategy is realized indirectly. To be indirect, Grice's maxims ${ }^{3}$ (1975) must be violated. Considering line 4 in Example 7, the student disagrees with his lecturer rather indirectly. The student violates the qualitative and relevance maxims in that his utterance is neither informative nor relevant to the content being discussed in the preceding utterances. In addition, the term "disagreement" has been defined variously (e.g. Sornig, 1977, Yule, 1996, Rees-Miller, 2000). Generally speaking, to disagree is to utter "Not P", i.e. not proposition that has been uttered, and thus is conventional. However, when the student performs his disagreement in line 4, the presence of "Not P" is not directly matched with the content uttered in line 3. In other words, "Not P" in line 4 does not aim to disagree with the preceding utterance directly. In fact, the student uses the conventional indirectness to perform her disagreement. Even though the speaker uses her native language, i.e. English, to perform the disagreement indirectly, it can be seen that prior to her initiation, the disagreement response in line 4 is not performed quickly. In opposition, it is prefaced with a delay, i.e. a long pause, providing evidence that the performance of disagreement indirectly can be costly (Dascal, 1983) and requires a certain amount of time before realizing it.

Example 7:

1. L: So: they won't come back RIGHT(I)=

2. $S:=$ : have no idea (a student shrugged her shoulder with a facial expression)

3. $L$ : (short pause) (p) they are very fast (p)

4. S: (long pause) oh you you're not usually late (short pause)

5. S: I was THINKING to leave too

6. S: And then I THOUGHT I have nothing to do

7. S: (s) so that's why I sit here (s)

8. L: (long pause) So:: in Canada (short pause) what do you do=

9. $\mathrm{L}:=$ if the professor comes late

10. S: NEVER never never

\section{Research Question}

In multiple disagreements, what politeness strategies do native speakers of Thai (the NT) and English (the NE) use to disagree with their lecturer in the classroom context and how are the strategies realized?

${ }^{3}$ To be cooperative in a conversation, both the speaker and the addressee are advised to observe Grice's Maxims, consisting of Maxims of Quality, Quantity, Relation and Manner. 


\section{Research Methodology}

\subsection{The Populations and Samples}

To answer the research question, two groups of populations are needed. They are (1) native speakers of Thai and (2) native speakers of English. I used the purposive sampling method to select two groups of samples representing the target populations, which are (1) the NT and (2) the NE. The former is a group of third-year undergraduate students from a state university in Thailand, while the latter is a group of third-year undergraduate students from a state university in Canada. Details of these participants and their classroom information are shown in Table 1.

Table 1: Information of the Samples and Classroom Context

\begin{tabular}{|l|l|c|c|}
\hline \multicolumn{2}{|l|}{} & The NT & The NE \\
\hline \multirow{4}{*}{ Demographic Information } & Male & 10 & 7 \\
\cline { 2 - 4 } & Female & 12 & 9 \\
\cline { 2 - 4 } & Nationality & Thai & Canadian \\
\cline { 2 - 4 } & First Language & Thai & English \\
\cline { 2 - 4 } & Age Range & $21-23$ & $20-22$ \\
\cline { 2 - 4 } & Level of Education & 3rd year undergraduate & 3 rd year undergraduate \\
\hline & & & 16 \\
\hline Classroom's Information & Number of Participants & 22 & 3 hrs/wk (9-12) \\
\cline { 2 - 4 } & Class Period & 3 hrs/wk (9-12) & Jan13-Apr13 \\
\cline { 2 - 4 } & Duration of Classroom Videotaping & Oct 12 -Jan 13 & Researcher \\
\cline { 2 - 4 } & Instructor & Researcher & English \\
\cline { 2 - 4 } & Medium of Instruction & Thai & \\
\hline
\end{tabular}

\subsection{The Research Instrument: Classroom Videotaping}

The videotape recording has potential to capture the samples' performance of disagreements in an authentic classroom environment. The naturally-occurring data are reported to have both advantages and disadvantages (e.g., Kasper \& Dahl, 1991; Cohen, 1996; Tseng, 1999; Yuan, 2001). On the one hand, the obtained data are spontaneous, reflecting what the speakers actually say rather than what they think they are supposed to say. As a result, the obtained data can be a source of rich pragmatic structures. On the other hand, there is no guarantee that sufficient samples of disagreement tokens can be found in a natural setting, particularly during the time when the classroom is videotaped. It may consume considerable time to collect the data. In addition, it is difficult to control contextual and social variables such as power, distance, gender and age in natural settings. Even though there are several disadvantages, I used the videotape recorder to gather the naturally-occurring disagreements from both classes of native speakers. The reason is that the principal objective of my study is to describe what politeness strategies native speakers of Thai and English and how the strategies are realized in authentic environments.

\subsection{Data Collection: Procedure}

Both classrooms of the NT and NE were videotaped for three hours every week within ten continuing weeks. Prior to the procedure of videotaping, an information sheet and a consent form were given to all samples providing instructions of my research project. The samples reserved the right to accept or refuse the invitation to be involved in the project at any time. There was no specification of any kind to notify the samples that their performance of disagreement was being observed and captured. All samples were aware that their general classroom conducts were observed. The videotape recorder was set up in front of the class fifteen minutes prior to the beginning of each class. It mainly captured the students' interactions with their lecturer.

\subsection{Data Analysis: Politeness Strategies}

All disagreement tokens were identified and transcribed. To begin with, I transcribed the disagreement tokens myself. After having transcribed all disagreement tokens, I requested two well-trained raters to validate the tokens whether the 
transcripts were accurate. The raters did not only validate the accuracy of my transcripts, but also categorized each disagreement token into an appropriate politeness strategy. In other words, the raters' validation increased the levels of reliability of the transcripts as well as the analyses. The transcripts began with the lecturer's initial utterance, which could be either a statement of opinion or a piece of fact, followed by the student's performance of disagreement as a responsive utterance. In my analysis, the focus was on the students' responsive utterance. Their utterances were analyzed in terms of the politeness strategies. Apart from analyzing each token in terms of its politeness strategy, the descriptions of how each politeness strategy is linguistically, paralinguistically and non-linguistically realized were also included.

\section{Study Results}

Results show that when the students' disagreement tokens are not drawn out by an elicited-based instrument, the NT and NE are able to perform student-lecturer multiple disagreements in the classroom context. Comparing their multiple disagreements, there is one similarity and two differences. The only similarity is that both the NT and NE usually initiate their multiple disagreements by using the on-record strategy. The two differences are (1) the NT and NE do not use the same politeness strategies in the subsequent turn(s). The NT, on the one hand, do not use the on-record strategy to continue their performance of disagreement. Their politeness strategy remains direct but they choose to redress the strategy towards the lecturer's positive or negative face-wants in the second disagreement. On the other hand, the NE's use of the on-record strategy in the second or following turns remain unchanged. The realization of the on-record strategy of the second and following turns tends to be aggravated. (2) The NT usually perform their disagreement in smaller numbers of turn-takings than those performed by the NE. The following sections present six examples to confirm the similarity and the differences.

\subsection{Similarity: The Use of the On-Record Strategy}

Both the NT and NE regularly begin their performance of disagreement by using the on-record strategy. Although the onrecord strategy is claimed to be the least appropriate politeness strategy (cf. Brown \& Levinson, [1978], 1987), it was used by both groups of native speakers, particularly at the beginning of their multiple disagreements. Examples 8 and 9 provide evidence to illustrate that the use of the on-record strategy addressed to the lecturer in the classroom context may be permissible and perhaps even acceptable cross-culturally.

Example 8: (the on-record strategy realized by the NT)

1. $L$ : เค๊าเลียนแบบนักพูดชื่อดัง (She has copied a famous speaker)

2. L: ชื่ออะไรนะ (What's her name?)

3. L: พยงค์ ที่เป็นผู้หญิงใส่แว่น (Payong, a female who wears glasses)

4. $\underline{\text { S: พเยาว์ (Payaaw) }}$

5. L: ไม่ใช่พยงค์เหรอ (Isn't she Payong?)

6. S: พยงค์ผู้ชายรึเปล่าค่ะ(Is Payong a male speaker?)

The lecturer shows the class a video clip of high-school students presenting their projects in public. One of the students in the video clip copies some characteristics of a famous Thai female speaker when presenting her work in front of her audience. The lecturer proposes his personal opinion for classroom discussion in line 1. He begins to ask the class about the famous speaker's name in line 2. The lecturer comes up with an incorrect name of that famous speaker. A student then begins her first disagreement in line 4, providing an explicit correction without any use of the negation marker in her utterance. This shows another possibility of realizing the on-record strategy directly. In other words, the NT's realization of the on-record strategy is not necessarily initiated by the negation marker. In this example, both the lecturer and the student share the same knowledge in that they both know who has been referred to. Although the lecturer has made a mistake, he is able to describe the famous speaker's characteristics correctly. The mistake is made because the two names, i.e. Payong and Payaaw, are similarly pronounced in Thai and they both are famous people in Thailand. Considering the lecturer's preceding utterance in line 2, he urges his students to provide a contribution to the classroom discussion. The question asking for a general contribution tends to have small ranking of imposition. As a result, to perform disagreement directly may not severely damage the lecturer's face. Example 9 also shows a similar case where the NE firstly use the on-record strategy in their multiple disagreements.

Example 9: (the on-record strategy realized by the NE) 
1. L: This is called snake beans (short pause) snake beans

2. S: Green peas green peas

3. L: It's called snake beans in English

4. S: (p) No (short pause) green peas (p) (a student shook his head from side to side)

The lecturer shows his class a picture of "snake beans" as an ingredient in papaya salad. To help the students memorize this vocabulary item, the lecturer introduces an English vocabulary that is believed to be literally equivalent to the Thai word. Based on the students' background knowledge, the closest word that may better explain the picture is not "snake beans" but "green peas". A student begins to disagree with his lecturer in line 2. He uses the on-record strategy to begin his multiple disagreements. He realizes the on-record strategy explicitly, aiming to state a different opinion by asserting new information to replace the lecturer's old information, i.e. snake beans. The student's linguistic realization is expressed unambiguously by repeating the new information twice. The student does not use any negation marker to initiate his disagreement. Repeating the utterance, i.e. "green peas green peas", has made the performance of disagreement direct. However, the lecturer's initial statement in line 1 is disagreeable because both the lecturer and the student do not necessarily share the same cultural knowledge (cf. Spir-Whorf hypothesis's linguistic relativity). In addition, the ranking of imposition is not high because the student's unshared knowledge is believed to be true in the student's culture. Considering the lecturer's content of discussion, he has attempted to propose his knowledge. As a result, the use of the on-record strategy serves a purpose to assert the student's different knowledge. Thus, it does not cause severe threats to the lecturer's face. Apart from looking at the similarity above, both groups of native speakers realize their politeness strategy in multiple disagreements differently.

\subsection{Dissimilarities}

\subsubsection{Different Politeness Strategy Used in the Subsequent Turn(s)}

One of the differences derives from the fact that the NT normally change their politeness strategy used in the second disagreement when performing the multiple disagreements with their lecturer. Example 10 illustrates such a claim.

Example 10: (politeness strategies used in multiple disagreements by the NT)

1. L: ชื่ออะไรนะครับ (What is your name?)

2. S: ฉัตรปรียาค่ะ (My name is Chatpreeya)

3. L: ชื่อเล่น (What is your nickname?)

4. $\mathrm{S}:$ นีน $=$ (Niin)

5. $\mathrm{L}:=$ นี (Nee?)

6. $\underline{\text { : }: \text { นีน (Niin) }}$

7. L: นิล (Nil)

8. $\mathrm{S}$ : (p) นีนค่ะ (p) (Niin $\left./ k^{h} \hat{N}\right)$

The lecturer asks a student to provide her personal information, i.e. her nickname, at the end of the class. When all students are about to leave the class, the classroom gets noisy, causing a difficulty for the lecturer to get what the student has said correctly. The same student performs multiple disagreements in lines 6 and 8 , aiming to correct the lecturer's mispronunciation of her nickname. The student's first disagreement in line 6 is performed to correct the mistake directly and explicitly. The student uses her background knowledge that is unshared with the lecturer together with her authority to correct such a mistake. This knowledge, i.e. the student's nickname, is unshared because her nickname is atypical among Thai female nicknames. The student does not use any negation marker to begin her disagreement, yet her performance of disagreement is rather direct. The student continues to disagree with the lecturer in line 8 , aiming to correct the lecturer's mispronunciation of her nickname again. The student does not use the on-record strategy in her second disagreement. Instead, the use of a Thai polite particle, i.e. $/ \mathrm{k}^{\mathrm{h}} \hat{N}^{4}$, shows that she values a certain level of deference and gives it to her lecturer, aiming to redress her direct strategy. The student does not want to impose on her lecturer's face. In addition, to utter the disagreement in a soft volume makes her disagreement less threatening than when uttered it in a louder volume. If the student disagreed with her lecturer in such a manner, it might deposit more

\footnotetext{
${ }^{4}$ There are two prominent gender-sensitive language features that show politeness in Thai. They are / $\mathrm{k}^{\mathrm{h}} \mathrm{n} \mathrm{p} / \mathrm{and} / \mathrm{k}^{\mathrm{h}} \hat{\mathrm{n}} /$. Both of them are normally used at the end of statements and questions to convey certain degrees of politeness and to show certain level of social distance (Srisuruk, 2011, p. 12).
} 
severe imposition on the lecturer's face and could be misinterpreted as sarcasm.

In opposition, the NE, although she begins the first disagreement with the on-record strategy, does not change her politeness strategy in the next turn(s) when performing multiple disagreements. However, the realizations of the onrecord strategy are strengthened and even aggravated, comparing to the strategies realized in previous turns. Example 11 reveals that the NE realize the same strategy, i.e. the on record strategy, differently in lines 4, 6, 8 and 9 when performing multiple disagreements.

Example 11: (politeness strategies used in multiple disagreements by the NE)

1. L: Give me another word that ends with -ness

2. S1: Sorrowfulness

3. L: Yea:h yea:h sorrowfulness

4. S2: No (the student shook her head from side to side) not a word

5. L: IT IS: (short pause) SORROWfulness is an English word

6. S2: SorrowfulNESS $(/)$ NO:... (the student shook her head from side to side)

7. L: It is in English

8. S2: (long pause) Not in English

9. S2: (long pause) Never heard of it

10. L: Really $(/)$

11. S2: I heard only SORROW

12. S2: (short pause) (p) It sounds really weird (short pause) sorrowfulness (p)

13. L: OK then (short pause) look it up in an online dictionary

The lecturer asks the students to introduce an English word that ends with the suffix "-ness". One of the students suggests "sorrowfulness", and the lecturer affirms its existence in English. Another student begins to disagree with the lecturer's assertion. Her disagreement begins in line 4, using the on-record strategy. She explicitly states her opinion that is contradictory to the lecturer's by uttering "No" as a negation marker, together with using her head shaking from side to side to support her disagreement. Her opposite opinion is caused by unshared background knowledge because the student has neither heard, nor seen the word before. In addition, she uses her authority in English as a native speaker to conclude that such a word does not exist in English. Her performance of disagreement in line 4 may not brutally threaten the lecturer's face because the suffix, i.e. "sorrowfulness", is originally given by another native speaker of English. The student's disagreement is carried out with no attempt to challenge her lecturer, but only to affirm the absence of such a word in English. Before performing her second disagreement in line 6, the student repeats the word out loud to recall it in her memory, when finally she is not familiar with the word. Her second disagreement is then performed. The negation marker "No", used to indicate the on-record strategy in line 6, is used again but it is not realized in a similar fashion. The lengthening vowel, i.e. "NO...." creates a word stress, making her disagreement in line 6 become more aggravated than the one realized in line 4 . The student still uses her head shaking to support the realization of the on-record strategy in line 6. The third disagreement in line 8 tends to impose on the lecturer's face because the student's disagreement is to declare the opposition towards the proposition uttered by the lecturer in line 7, i.e. "It's in English" by "Not in English". The student uses her authority in English together with her personal background knowledge to insist on the third disagreement. The lecturer thus suggests that the student look it up in a dictionary (and she finally finds it).

Based on Example 11, apart from the possible realization of the on-record strategy initiating with a negation marker, i.e. No, there are two other negation markers that are used by the NE. They are (1) Not and (2) Never. In addition, the use of certain paralinguistic features, e.g. lengthening vowels, can aggravate the degree of seriousness (cf. Rees-Miller, 2000; Kakava, 2002; Hong, 2003). Furthermore, the negation marker, "No" realized by the NE, is usually accompanied by the head gesture of shaking it from side to side. This is to show that linguistic realization can be supported by both paralinguistic features and head gesture.

Another difference deals with the total number of turns in conversational exchanges between the lecturer and the student. Basically speaking, both the NT and NE, when performing multiple disagreements, always aim to present their different opinions or provide a correction. To perform such disagreement, the NT and NE develop multiple turns in significantly different lengths before they have achieved their objective (i.e. to convince their lecturer and to correct his mistakes).

\subsubsection{Total Number of Turn-Takings}

Examples 12 and 13 illustrate different numbers of turn-takings that the students contribute to their conversational 
exchanges when performing multiple disagreements. The NT normally produce relatively few turn-takings and they normally take a passive role in their conversational exchanges. The NT do not initiate their talks in multiple disagreements. Example 12 provides evidence that the NT rarely perform the multiple disagreements in many turns. Based on the given example, the NT tend to be silent and do not further their disagreement without the lecturer's elicited question (cf. line 5 in Example 12). In order to elicit their multiple disagreements, the lecturer normally uses a question to prompt the student for the next performance of disagreement.

Example 12: (numbers of turns produced by the NT)

1. L: เพราะเวลาที่ถามคำถามนี้ (short pause) (Because when I have asked my students this question)

2. L: ทุกคนจะตอบว่าเทคโนโลยีสำคัญกว่าวัฒนธรรม ทุกคนเลย (All students always answer that the technology is more important than the culture, everyone says that)

3. S: (student shook his head) (p) ไม่ใช่ วัฒนธรรมสำคัญกว่า (p) (No, the culture is more important)

4. Ss: (long silence)

5. L: ทำไมมันจึงสำคัญกว่า (Why is it more important?)

6. S: (short pause) เพราะว่า ถึงแม้ว่าคนจะมองว่าประเทศจะพัฒนาได้ เทคโนโลยีเป็นส่วนสำคัญ (Because although people perceive that to develop a country depends largely on the technology)

7. S: แต่ว่า (long pause) บางประเทศ อย่างเช่นประเทศลาว ก็ได้รับว่าโดดเด่นทางด้านวัฒนธรรม (in some countries such as Laos where its culture is distinctively unique)

8. S: ถึงแม้ว่าจะเป็นประเทศไม่เเริญก็ตาม (Although it is not a developed country)

Example 12 shows that the student does not take an active role in this conversational exchange with his lecturer. The student's first disagreement in line 3 is rather simple and short. To mark his disagreement, the student realizes the on-record strategy by using a negation marker, i.e. ไม่ใช่ [or literal translation "No"]. To further acquire a longer justification and critical disagreement, the lecturer uses an eliciting question, i.e. Why is it more important? Based on Example 12, it can be seen that the students do not have an initiative role in their conversational exchanges and frequently play a passive role in the interaction.

Oppositely, the NE are more active when performing the disagreement with their lecturer in many turns, making the total number of turn-takings increased. Below is an example where the NE perform the student-lecturer multiple disagreement. Obviously, the student plays an initiative role raising a topic of discussion. The student contributes twentysix turns out of forty-two to carry out her conversation with the lecturer. Her role in this conversation is clearly active. The lecturer does not always have a role to initiate the talks and sometimes the lecturer's role is shifted to that of providing back-channeling (cf. lines 19 and 21). Without the lecturer's active role in this conversation, the student is able to begin and continue her talks to a considerable length.

Example 13: (numbers of turns produced by the NE)

1. S: How do you say spicy's OK (long pause)

2. S: BeCAUSE lots of time when we go:

3. S: And we order spicy and that's tasteless

4. L: (long pause) $/ \mathrm{p}^{\mathrm{h}} \mathbf{3} \mathrm{d} /=$

5. $\mathrm{S}:=1 \mathrm{know} / \mathrm{p}^{\mathrm{h}} \mathrm{àd} /$

6. S: BUT how do I say (short pause) I don't want TOO spicy

7. S: (short pause) I want OK spicy

8. S: (long pause) that's what I want to say

9. L: /maî phàd ma:kl=

10. $\mathrm{S}:=$ NO I WANT spicy=

11. L: =Yeah BUT you want NOT TOO spicy

12. S: NO:: I want how they make it FOR (short pause) YOU

13. S: BUT they won't make it like THAT for me

14. L: /maî phàd mâ:k/

15. L: /maî/ means not /phàd/ means spicy /mâ:k/ means too much

16. L: (short pause) not too much spicy

17. S: (short pause) NO no no (she shook her head from side to side)

18. S: BECAUSE I am "farang"

19. L: YES

20. S: Sometimes they make my dishes NOT TOO spicy 
21. L: YES

22. S: They thought l've never had it before

23. S: So how do I say to them to make it REGULAR

24. L: yes I know BUT IF you say "phed"

25. L: maybe (short pause) it's TOO spicy

26. S: (short pause) I want them to NOT think=

27. S: =that I can't have spicy you know

28. S: because that's my problem

29. L: OH oh you can probably say spicy BUT NOT TOO MUCH

30. L: It means it's spicy but not as for Thai people

31. S: No no no no (she shook her head from side to side with a stern facial expression)

32. S: I can have it as spicy AS Thai PEOple

33. L: SO: (short pause) just say /phàd/

34. S: $/ p^{h} 3 \grave{d} /(I)$

35. L: umh /phàd//phàd/

36. S: /ph $3 \mathrm{~d} /$ and smile maybe (laughs)

37. L: Because in Thai IF WE repeat the word twice (short pause)

38. L: Then it means=

39. S: =too much

40. S: OK I'll just say THAT

41. S: And just SMILE

42. S: Oka::y (laughs) thank you

The relatively long conversation has been carried out by the lecturer and one student. There are forty-two utterances that have been performed by both interlocutors. The student contributes twenty-six turns in this conversational exchange, while the lecturer contributes only sixteen turns. The student initiates the conversation by asking how to say "spicy is OK for her" in Thai. The lecturer tries to introduce several short phrases and explains to her in English but she does not want the lecturer's suggestions. She thinks that the suggestions are not what she wants to say in Thai. In example 13, the same student performs the disagreement four times (cf. in lines 10,12, 17 and 31), enlarging the total number of turn-taking.

\section{Conclusion}

Results from the classroom videotaping have shown that both the NT and NE are able to perform the student-lecturer multiple disagreements in the classroom context. The on-record strategy, despite being the least appropriate politeness strategy (cf. Brown \& Levinson, [1978], 1987), is used very frequently by both groups of native speakers to initiate their multiple disagreements. Results have illustrated that possible realizations of the on-record strategy are relatively simple and do not require any sophistication in order to realize them directly. It can be an advantage of using the on-record strategy to initiate a first disagreement. In addition, rankings of imposition based on the contents of utterances addressed by the lecturer tend to be low. Frequently, the student's performance of disagreement is encouraged by the lecturer, aiming to declare that the students' disagreement is wanted and allowed. The use of the on-record stratgey is thus permissible with the lecturer in the classroom context. However, the NT and NE do not perform their multiple disagreements after the initiating disagreement in an identical fashion. The NT normally use other direct strategies with redressive actions, either towards the positive politeness strategy or the negative politeness strategy, to continue their multiple disagreements, while the NE usually aggravate the on-record strategy in the subsequent turns. Furthermore, the NT rarely engage in opening the conversational exchanges to perform their disagreement actively, whereas the NE play an active role to initiate their multiple disagreements as well as to interact with their student-lecturer disagreement enthusiastically. These differences have indeed proved to be caused by their different culture-oriented backgrounds, i.e. the collectivism versus the individualism, which are claimed to govern their linguistic behaviors.

\section{References}

Brown, P., \& Levinson, S. (1978). Universals in language use: Politeness phenomena. In E. N. Goody (Ed.), Questions and politeness: Strategies in social interaction (pp. 56-289). New York: Cambridge University Press.

Brown, P., \& Levinson, S. (1987). Politeness: Some universal in language usage. Cambridge: Cambridge University Press. 
Chen, M. (2006). An Interlanguage study of the speech act of disagreement made by Chinese EFL speakers in Taiwan. Unpublished doctoral dissertation. National Sun Yat-Sen University.

Cohen, D. A. (1996). Developing the ability to perform speech acts. Studies in Second Language Acquisition, 18 (2), $253-267$.

Dascal, M. (1983). Pragmatics and the philosophy of mind, Thought in language. Amsterdam: John Benjamins.

Grice, H. P. (1975). Logic and conversation. In P. Cole \& J.L. Morgan (eds.), Syntax and semantics, vol. 3: Speech acts. New York: Academic Press, pp. 41-58.

Guodong, L., \& Jing, H. (2005). A contrastive study on disagreement strategies for politeness between American English and Mandarin Chinese. ASLAN EFL Journal, $7(1), 1-12$.

Hofstede, G. (1991). Cultures and organizations: Software of the mind. London, UK: McGraw-Hill.

Hofstede, G. (2001). Cultures and organizations: Software of the mind. London, UK: McGraw-Hill.

Hong, J. Y. (2003). Interactional sociolinguistic analysis of argumentative strategies between Japanese and Korean graduate students and their instructors. PAAL, 7, 98-124.

Kakava, C. (1993). Negotiation of disagreement by Greeks in conversations and classroom discourse. Unpublished Dissertation, Georgetown University Washington D.C.

Kakava, C. (2002). Opposition in Modern Greek discourse: Cultural and contextual constraints. Journal of Pragmatics, 34, $1537-1568$.

Kasper, G., \& Dahl, M. (1991). Research methods in interlanguage pragmatics. Studies in Second Language Acquisition, 13, $215-247$.

Leech, G. (1983). Principles of Pragmatics. New York: Longman.

Liu, S. (2004). Pragmatic strategies and power relations in disagreement: Chinese culture in higher education. Boca Raton: University Publishers.

Locher, A. M. (2004). Power and politeness in action: Disagreements in oral communication. Berlin: Mouton de Gruyter.

Pomerantz, A. (1984). Agreeing and disagreeing with assessments: Some features of preferred/dispreferred turn shapes. In J. Maxwell Atkinson \& J. Heritage (Eds.), Structures of social action: Studies in conversation analysis. (pp. 57-101). Cambridge: Cambridge University Press.

Rees-Miller, J. (2000). Power, severity and context in disagreement. Journal of Pragmatics, 32, 1087-1111.

Sacks, H. (1987). On the preferences for agreement and contiguity in sequences in conversation. In G. Button \& J. R. E. Lee (Eds.), Talk and social organization (pp. 54-69). Clevedon, England: Multilingual Matters.

Schiffrin, D. (1984). Jewish argument as sociability. Language in Society, 13, 311-335.

Schiffrin, D. (1987). Discourse markers. Cambridge: Cambridge University Press.

Sornig, K. (1977). Disagreement and contradiction as communicative acts. Journal of Pragmatics, 1, 347-374.

Thi Thu Huong, K. (2006). Disagreeing in English and Vietnamese: A pragmatic and conversational analysis perspective. Unpublished doctoral dissertation. Vietnam National University.

Tseng, S. (1999). Grammar, prosody and speech disfluencies in spoken dialogues. Unpublished doctoral dissertation. University of Bielefeld.

Walkinshaw, I. (2007). Power and disagreement: Insights into Japanese learners of English. RELC Journal. 38, 278-300.

Walkinshaw, I. (2009). Learning politeness: Disagreement in a second language. Oxford: Peter Lang. Wierzbicka, A. (1991). Crosscultural pragmatics: The semantics of human interaction. Berlin: Mouton de Gruyter.

Xuehua, W. (2006). A study of strategy used in showing agreement and disagreement to other opinions. CELEA Journal, 29 (5), 55-65.

Yuan, Y. (2001). An inquiry into empirical pragmatics data-gathering methods: written DCTs, oral DCTs, field notes, and natural conversations. Journal of Pragmatics, 33, 271-292.

Yule, G. (1996). Pragmatics. Oxford: Oxford University Press.

\section{Appendix I:}

The conventions of paralinguistic features used in the study, adapted from Locher (2004)

$1 \quad:$ A period is used to indicate a falling intonation.

I : : A question mark is used to indicate a raising intonation.

CAPS $\quad:$ : Capital letters carry the primary stress in a monosyllable word.

$=\quad:$ In order to show an immediate connection between two turns uttered by the lecturer and the student.

:... : Colons are used to indicate lengthening vowels

[...] : : Square brackets indicate speech overlap uttered by lecturer and student or vice versa.

@ : : This symbol is used to represent laughter in syllable.

$X \quad$ : The letter $X$ indicates an unclear or unintelligible syllable or word.

a...a : Utterances marked by this are rapid speech.

s...s : Utterances marked by this are slow speech.

p...p : : Utterances marked by this are soft.

@...@ : Utterances marked by this are produced with laughs. 